\title{
Assessment of Quality of Life Related to the Health of People Suffering from Chronic Diseases in Ouémé Department of Benin
}

\author{
Tévoédjrè Doréana Frida ${ }^{1, *}$, Paraïso Moussiliou ${ }^{2}$, Gouthon Polycarpe ${ }^{1}$, Gouthon Fabrice Gilchrist ${ }^{1}$, \\ Tonon Affidéhomé Brigitte ${ }^{1}$, Ouendo Edgard-Marius Dona ${ }^{2}$ \\ ${ }^{1}$ Sports, Health and Evaluation Research Unit, National Institute of Youth, University of Abomey-Calavi, Benin \\ ${ }^{2}$ Regional Institute of Public Health, University of Abomey-Calavi, Benin
}

Received July 31, 2019; Revised August 28, 2019; Accepted September 20, 2019

Copyright $\odot 2019$ by authors, all rights reserved. Authors agree that this article remains permanently open access under the terms of the Creative Commons Attribution License 4.0 International License

\begin{abstract}
Measuring health-related quality of life (HRQoL) facilitates the monitoring and evaluation of the population's health status, and country's public health policies. Studies undertaken in the Republic of Benin on this issue are quite rare. Objective: The objective is to study the level of HRQoL in people with chronic communicable or non-communicable diseases at the Ouémé department in Benin. Method: This is a cross-sectional and analytical survey conducted at this department in 2018. Medical Outcomes Study SF-36 questionnaire was administered to 523 people over 15 years of age who were suffering from chronic disease, and they were selected by the snowball technique. The level of HRQoL defined in three modalities was determined from the four dimensions of each of its physical and mental components. Results: In the Ouémé department, eight chronic diseases were identified and the level of HRQoL appeared higher in rural areas for hypertension, sickle cell disease and sinusitis. In total, $73.8 \%$ of people with chronic diseases had high levels of HRQoL. The level of HRQoL was higher in rural areas than in urban areas $(85.2 \%$ versus $64.8 \% ; \mathrm{p}<0.0001)$. Interventions on HRQoL at the Ouémé department must take into account the disparities between urban and rural areas.
\end{abstract}

Keywords Rural Area, Urban Area, Mental Health, Physical Health, Health Policy

\section{Introduction}

Western societies are increasingly concerned about the quality of life in different segments of the population. In Europe, administrative authorities develop programs to improve the quality of life of a particular segment of the population or of all citizens (Bucquet, 1993). The quality of life influenced by physical and mental health is called Health-Related Quality of Life (HRQoL) (Ferrans, 2005). HRQoL is lower in people with diabetes than in people without diabetes (Tulza, 2017). It has been observed that people with high blood pressure have a lower HRQoL than normotensive people (Zhang et al., 2017) and patients with diabetic foot ulcers have a poor health-related quality of life (Alrub, 2019). Therefore, the WHO has considered improving the quality of life of people with chronic diseases a priority, for this reason, the elements of interpretation and understanding in patients with chronic diseases were evaluated in large cross-sectional epidemiological surveys (Detmar, Muller, Schornagel, Wever \& Aaronson, 2002). The evaluation and monitoring of HRQoL in general population of Benin are considerable interest. The measurement and identification of variables that affect HRQoL are crucial to determine health disparities, guide health professionals and decision-makers towards appropriate intervention strategies to improve HRQoL (Slim, Bousquet \& Kwiatkowski, 1999).

HRQoL is influenced by variables, such as age and gender (Le Glatin, Hervy, Guillaume \& Traboulsie, 2017), monthly income (Jang et al., 2018), occupational status (Tu, Hwang, Ma, Chang \& Hsule, 2017), and geographic location of populations ( $\mathrm{Gu}$ et al., 2019). The main objective of the majority of available studies was to evaluate the HRQoL for a specific sample of patients and identify the factors that determine it or are simply associated with it. The relationship between patients' living environment and their level of HRQoL is less focused on studies. Furthermore, these studies have not reported the HRQoL, to facilitate the stratification of HRQoL in people with chronic disease in a given region. This approach 
makes it possible to identify the groups that need intervention programs as a priority. Therefore, the aim of this study is to: 1) determine the level of HRQoL for each chronic disease identified in rural and urban areas at the Ouémé department in Benin; 2) determine the level of dimensions, components and the HRQoL in both environments; and 3) assess the influence of the living environment on this health-related quality of life at the department studied.

\section{Methods}

This is a cross-sectional study, conducted from October to November 2018, with an analytical focus in the form of a questionnaire survey of people with chronic diseases. The questionnaire was self-administered, either in the health center where these patients were attending or at home, under the supervision of two previously trained interviewers and the principal investigator. The questionnaire was immediately removed after completion. When respondents were illiterate, the answers were transcribed on the forms by the interviewers.

The target population consisted of people (men and women) suffering from chronic diseases at the Ouémé department in Benin. A sample of 523 patients, 267 male and 256 female, was collected using the snowball technique. People with chronic disease were included in the study who were 15 years of age or older, diagnosed by a health professional, consulted in one of the health centers chosen for the study with an address that could be easily reached. People identified, but deceased or are outside the country, those whose addresses did not allow them to be found and all those who decided not to participate in this study, were excluded. Steps have been taken to ensure the anonymity of the patients interviewed, as well as the confidentiality of the data collected. All of the patients gave their informed and verbal consent.

The approval of the Scientific Committee of Sciences and Techniques of Physical and Socio-Educational Activities of the University of Abomey-Calavi had previously been required. The survey was carried out with the SF-36 questionnaire, also known as the Medical Outcomes Study SF-36. The validity of the SF-36 questionnaire showed excellent internal consistency, with Cronbach alpha coefficients generally exceeding 0.80 for all dimensions, except for the one related to social functioning (McHorney, Ware, Lu \& Sherbourne, 1994). The correlation coefficients calculated the consistency of the data over time in test-retest ranged from adequate with $r$ $=0.60$ for social functioning to excellent, with $\mathrm{r}=0.81$ for physical functioning. Thus, the results of the evaluation of fidelity of the SF-36 test-retest questionnaire suggest that the scores recorded are well reproducible (Brazier, Harper \& Jones, 1992).

The questionnaire is composed of 36 items, divided into the two physical and mental components of the HRQoL as a composite variable. The physical component includes four dimensions: physical functioning, role physical, body pain, and general health. The dimensions of the mental component refer to vitality, social functioning, role emotional and mental health. All the data collected were used to determine the level of HRQoL based on the scores calculated for the various dimensions and components selected. The level of each of the components, as well as that of the HRQoL, was made operational in three ways: high level for $\geq$ scores 80 points (Varkevisser, Pathmanathan \& Brownlee, 1991), medium level for $\geq$ scores 60 points and $<80$ points, and then low level for scores $<60$ points. The data were processed with the SPSS software (IBM, version 21.0).

Descriptive statistics was calculated to determine the relative frequencies of different variables and sub-variables. The association between the sub-variables, and the level of HRQoL on the one hand and the place of residence on the other hand, were determined using the test of $\chi^{2}$. V of Cramer was calculated to assess the strength of the association, in cases where the $\chi^{2}$ test was significant. The level of significance of the statistical tests was set at $p<$ 0.05 .

\section{Results}

Eight chronic diseases common to both urban and rural areas were identified during a pre-survey. They are as follows: high blood pressure, type 2 diabete, peptic ulcer, sickle cell disease in the SS and SC forms, asthma, sinusitis, hepatitis B and C, and AIDS. The level of HRQoL (Table 1) was higher in rural patients than urban patients for high blood pressure $(p=0.001)$ and sickle cell disease $(p=0.04)$. The level of HRQoL (Table 2) was higher in rural areas than in urban areas $(\mathrm{p}=0.003)$ for sinusitis patients only. For the other five diseases, the association between the level of HRQoL and place of residence was insignificant $(p>0.05)$. 
Table 1. Association between HRQoL and chronic diseases directly related to blood $(n=523)$

\begin{tabular}{|c|c|c|c|c|c|}
\hline Diseases and level of HRQoL & Urban area & Rural area & $\chi^{2}$ & $\mathbf{P}$ & V of Cramer \\
\hline \multicolumn{6}{|l|}{ High blood pressure } \\
\hline - High & $55(60,4)$ & $76(83,5)$ & & & \\
\hline - Medium & $11(12,1)$ & $7(7,7)$ & 13,01 & 0,001 & 0,26 \\
\hline - Low & $25(27,5)$ & $8(2,8)$ & & & \\
\hline \multicolumn{6}{|l|}{ Sickle cell disease SS et SC } \\
\hline - High & $5(45,5)$ & $25(73,5)$ & & & \\
\hline - Medium & $0(0,0)$ & $3(8,8)$ & 6,19 & 0,04 & 0,37 \\
\hline - Low & $6(54,5)$ & $6(17,7)$ & & & \\
\hline \multicolumn{6}{|l|}{ Type 2 diabete } \\
\hline - High & $91(63,6)$ & $8(88,9)$ & & & \\
\hline - Medium & $20(14,0)$ & $0(0,0)$ & 2,58 & 0,27 & - \\
\hline - Low & $32(22,4)$ & $1(11,1)$ & & & \\
\hline \multicolumn{6}{|l|}{ AIDS } \\
\hline - High & $1(100,0)$ & $0(0,0)$ & & & \\
\hline - Medium & $0(0,0)$ & $0(0,0)$ & 2,00 & 0,15 & - \\
\hline - Low & $0(0,0)$ & $1(100,0)$ & & & \\
\hline
\end{tabular}

HRQoL: health-related quality of life

Table 2. Association between HRQoL and chronic diseases not directly related to blood $(\mathrm{n}=523)$

\begin{tabular}{|c|c|c|c|c|c|}
\hline Diseases and level of HRQoL & Urban area & Rural area & $\chi^{2}$ & $\mathbf{P}$ & V of Cramer \\
\hline \multicolumn{6}{|l|}{ Peptic ulcer disease } \\
\hline - High & $23(82,2)$ & $43(89,6)$ & & & \\
\hline - Medium & $2(7,1)$ & $1(2,1)$ & 1,36 & 0,50 & - \\
\hline - Low & $3(10,7)$ & $4(8,3)$ & & & \\
\hline \multicolumn{6}{|l|}{ Asthma } \\
\hline - High & $0(0,0)$ & $6(85,7)$ & & & \\
\hline - Medium & $1(50,0)$ & $1(14,3)$ & 1,14 & 0,28 & - \\
\hline - Low & $1(50,0)$ & $0(0,0)$ & & & \\
\hline \multicolumn{6}{|l|}{ Hepatitis B et C } \\
\hline - High & $6(100,0)$ & $22(88,0)$ & & & \\
\hline - Medium & $0(0,0)$ & $2(8,0)$ & 0,79 & 0,67 & - \\
\hline - Low & $0(0,0)$ & $1(4,0)$ & & & \\
\hline \multicolumn{6}{|l|}{ Sinusitis } \\
\hline - High & $3(60,0)$ & $21(100,0)$ & & & \\
\hline - Medium & $0(0,0)$ & $0(0,0)$ & 9,10 & 0,003 & 0,59 \\
\hline - Low & $2(40,0)$ & $0(0,0)$ & & & \\
\hline
\end{tabular}

HRQoL: health-related quality of life.

Each of the four dimensions of the physical and mental components of HRQoL showed a significant association ( $p$ $<0.05$ ) with the residence environment. Regard to the physical component (Table 3), the number of people with high levels of all four dimensions was higher in rural areas than urban areas $(\mathrm{p}<0.05)$. For the mental component (Table 3), patients with medium levels of vitality and mental health were also more in number in urban than rural areas $(\mathrm{p}<0.05)$. The number of people with high levels of social functioning and emotional role were higher in rural areas than urban areas $(\mathrm{p}<0.05)$.

It has been observed that there were more people with high levels of the physical and mental components of HRQoL (Table 4) in rural areas than urban areas $(p<0.05)$.

At the Ouémé department, $73.8 \%$ of people with chronic diseases had a high level of the QVLS. Finally, in general (Table 4), the level of HRQoL was higher in rural than urban areas for people with chronic diseases $(p<0.0001)$. 
Assessment of Quality of Life Related to the Health of People Suffering from Chronic Diseases in Ouémé Department of Benin

Table 3. Association between HRQoL dimensions and place of residence $(\mathrm{n}=523)$

\begin{tabular}{|c|c|c|c|c|c|}
\hline Dimensions & $\begin{array}{c}\text { Urban area } \\
\text { Number (\%) }\end{array}$ & $\begin{array}{c}\text { Rural area } \\
\text { Number (\%) }\end{array}$ & $\chi^{2}$ & $\mathbf{p}$ & V of Cramer \\
\hline & \multicolumn{2}{|c|}{ Physical component } & & & \\
\hline \multicolumn{6}{|l|}{ Level of PF } \\
\hline - High & $190(65,1)$ & $190(82,2)$ & 19,69 & $<0,0001$ & 0,19 \\
\hline - Medium & $9(3,1)$ & $2(0,9)$ & & & \\
\hline - Low & $93(31,8)$ & $39(16,9)$ & & & \\
\hline \multicolumn{6}{|l|}{ Level of RP } \\
\hline - High & $209(71,6)$ & $206(89,2)$ & 24,98 & $<0,0001$ & 0,21 \\
\hline - Medium & $1(0,3)$ & $1(0,4)$ & & & \\
\hline - Low & $82(28,1)$ & $24(10,4)$ & & & \\
\hline \multicolumn{6}{|l|}{ Level of BP } \\
\hline - High & $194(66,4)$ & $190(82,2)$ & 16,92 & $<0,0001$ & 0,18 \\
\hline - Medium & $56(19,2)$ & $26(11,3)$ & & & \\
\hline - Low & $42(14,4)$ & $15(6,5)$ & & & \\
\hline \multicolumn{6}{|l|}{ Level of GH } \\
\hline - High & $17(5,8)$ & $116(50,2)$ & 165,85 & $<0,0001$ & 0,56 \\
\hline - Medium & $149(51,0)$ & $100(43,3)$ & & & \\
\hline \multirow[t]{2}{*}{ - Low } & $126(43,2)$ & $15(6,5)$ & & & \\
\hline & \multicolumn{2}{|c|}{ Mental component } & & & \\
\hline \multicolumn{6}{|l|}{ Level of Vitality } \\
\hline - High & $13(4,4)$ & $99(42,9)$ & 114,79 & $<0,0001$ & 0,46 \\
\hline - Medium & $230(78,8)$ & $116(50,2)$ & & & \\
\hline - Low & $49(16,8)$ & $16(6,9)$ & & & \\
\hline \multicolumn{6}{|l|}{ Level of SF } \\
\hline - High & $205(70,2)$ & $200(86,5)$ & 20,06 & $<0,0001$ & 0,19 \\
\hline - Medium & $53(18,2)$ & $17(7,4)$ & & & \\
\hline - Low & $34(11,6)$ & $14(6,1)$ & & & \\
\hline \multicolumn{6}{|l|}{ Level of RE } \\
\hline - High & $228(78,1)$ & $210(90,9)$ & 15,63 & $<0,0001$ & 0,17 \\
\hline - Medium & $4(1,4)$ & $1(0,4)$ & & & \\
\hline - Low & $60(20,6)$ & $20(8,7)$ & & & \\
\hline \multicolumn{6}{|l|}{ Level of MH } \\
\hline - High & $21(7,2)$ & $35(15,1)$ & & & \\
\hline - Medium & $249(85,3)$ & $188(81,4)$ & 11,59 & 0,003 & 0,14 \\
\hline - Low & $22(7,5)$ & $8(3,5)$ & & & \\
\hline
\end{tabular}

PF: Physical Functioning; RP: Role Physical; DP: Body Pain; GH: General Health; SF: Social Functioning; RE: Role Emotional; MH: Mental health.

Table 4. Association between the level of the HRQoL, then its components and the place of residence $(\mathrm{n}=523)$

\begin{tabular}{|c|c|c|c|c|c|}
\hline Components of HRQoL & $\begin{array}{c}\text { Urban area } \\
\text { Number (\%) }\end{array}$ & $\begin{array}{c}\text { Rural area } \\
\text { Number (\%) }\end{array}$ & $\chi^{2}$ & p & V of Cramer \\
\hline Physical component & & & & & \\
\hline - High level & $190(65,0)$ & $191(82,7)$ & & $<0,0001$ & 0,23 \\
\hline - Medium level & $22(7,5)$ & $20(8,6)$ & 29,38 & & \\
\hline - Low level & $80(27,4)$ & $20(8,7)$ & & & \\
\hline Mental component & & & & & \\
\hline - High level & $184(60,0)$ & $205(88,8)$ & & & \\
\hline - Medium level & $49(16,8)$ & $7(3,0)$ & 46,66 & & \\
\hline - Low level & $59(20,2)$ & $19(8,2)$ & & & \\
\hline Level QVLS & & & & & \\
\hline - High level & $189(64,8)$ & $197(85,2)$ & & & \\
\hline - Medium level & $34(11,6)$ & $14(6,1)$ & 28,50 & & \\
\hline - Low level & $69(23,6)$ & $20(8,7)$ & & & \\
\hline
\end{tabular}

HRQoL: health-related quality of life. 


\section{Discussion}

Health-related quality of life (HRQoL) for people with chronic diseases at the Ouémé department varies according to the condition, depending on whether the person lives in an urban or rural environment. It is on the basis of this hypothesis that the present study was carried out, using the SF-36 questionnaire, which shows good levels of fidelity and consistency over time, thus making the data collection from a random sample sufficiently reliable. In addition, the snowball technique used for sampling allows the results to be generalized, but the fact that the cross-sectional approach was chosen could be considered as a limitation of the study. Indeed, the approach used does not allow us to assess the evolution of HRQoL in people with chronic diseases in the study department. Relevant factors such as demographics, marital status, education, socio-economic status and social support, particularly the frequency of contact, which is at the heart of social relationships, can help explain the difference in HRQoL between urban and rural residents (Liu \& Guo, 2007).

The general observation established at Ouémé department is that the level was higher in rural areas than in urban areas for three of the different diseases studied, as well as for the physical and mental components and the HRQoL itself. This difference can be explained by biological and genetic factors, as well as social factors such as education, occupation and income that affect the health of men and women (Denton, Prus \& Walters, 2004).

Several studies have reported that regional difference is an important factor related to health status and have shown that there are inequalities between regions and areas in terms of health status (Sun et al., 2011). In urban areas, household income changes with the standard of living over time, while in rural areas, it increases with social class (INSAE, 2015). An important difference between the rural and urban areas is also in the sense of belonging to their community, which appears stronger in rural areas and also affects health status (Bussières, 2005). The vast majority of people with chronic diseases in this department who live in rural areas belong to the informal sector. Several previous studies have shown that the informal sector is more represented in rural areas, due to the importance of agricultural activities (INSAE, 2012).

The level of HRQoL was higher in rural areas than urban areas for people with high blood pressure, sickle cell disease and sinusitis at Ouémé department. A statistically significant difference in HRQoL was observed in rural and urban patients with high blood pressure in Shaanxi, China, indicating that patients in the urban area may have a higher HRQoL than patients in the rural area (Zhang et al., 2016). The cross-sectional study conducted among the rural Chinese population of Jiangsu with hypertensive people showed that the HRQoL was lower in this population than in patients with hypertension living in the city (Liang et al., 2019). However, the results of this study contradict with these results. Allergic rhinitis and rhinosinusitis have caused a decrease in HRQoL in Korean adults (Shin et al., 2018). Sickle cell patients in Colombia have low levels of HRQoL (Romero, Sanabria \& Huerfano, 2016). The work reported in the literature on sinusitis and sickle cell disease has mostly been limited to determining the influence of these diseases on HRQoL and has not focused the residential environment effect.

At the Ouémé department, the physical and mental components of HRQoL are higher in rural areas than urban areas. In the United States, the physical and mental components were significantly lower for veterans living in rural areas than for those living in urban areas (Weeks et al., 2004). The results reported in literature differ from those obtained in this study, because the work focused on populations that did not necessarily have a chronic disease. Compared to the group of chronically ill urban veterans, those in rural areas had low levels of physical and mental components of HRQoL (Weeks et al., 2006). However, the results obtained in the Ouémé department contradict with this last observation. The difference observed may be explained by the fact that in this study, the components were determined from data collected from adults with chronic diseases, who do not necessarily have the same characteristics as veterans.

Finally, in this study, the level of HRQoL was higher in rural areas than the urban one for people with chronic diseases. This finding is consistent with those of other authors, since, in India, HRQoL was lower and affected more people with periodontal disease in rural areas than their urban counterparts (Grover, Malhotra, Dhawan, Kaur \& Kapoor, 2015). This can be explained by the fact that in the literature, HRQoL was determined from data collected from adults with chronic diseases that are not the same as those identified at the Ouémé department. Unlike the data in this study, the HRQoL in elderly people with chronic diseases in rural areas of Guangdong province was poor or low (Zhou et al., 2014).

\section{Study Limit and Strengths}

The fact that the cross-sectional approach was chosen could be considered as a limitation of the study, since the approach used does not make it possible to assess the evolution of HRQoL in people with chronic diseases for a given period in study area. Second, socio-demographic variables that could help explain the difference between rural and urban areas were not included in the study design.

This is one of the first studies to assess the relationship between the living environment of people with chronic disease and their level of HRQoL in sub-Saharan Africa. In this study, the HRQoL was made operational at 3 levels of stratification, i.e. high, medium and low. This approach made it possible to refine the analysis and highlight the role that the environment plays in achieving a good quality of 
life for these people.

\section{Recommendation for Further Research}

The study reported in the literature has for the most part been limited to determining the influence of these pathologies on HRQoL and has not highlighted the residential environment effect. The hypothesis formulated in the context of this study was confirmed by the results recorded at the Ouémé department. This study provides a normative database for the SF-36 questionnaire and these data could be used to guide interventions on HRQoL in populations with chronic disease. Additionally, the next research have to include prospective and intervention study design making it possible to monitor favorable evolution of HRQoL in any population with chronic disease. This study also needs to be conducted indigenously and in context to global research.

\section{Conclusions}

The objectives of this study were to determine the level of health-related quality of life (HRQoL) and its components among people with chronic diseases at the Ouémé department and to assess the influence of the residential environment on this quality of life. For this purpose, a survey was conducted among patients suffering from eight pre-identified diseases, using the SF-36 questionnaire.

The data collected showed that the level of HRQoL was higher in rural areas than in urban areas among people with hypertension, sickle cell disease and sinusitis. In general, the level of the general HRQoL and its components were also higher among people in rural areas with chronic disease, than among those in urban areas.

The results of this study can be considered as normative data and reference data from the SF-36 questionnaire that can be used in the short term for comparison with those of specific populations. In this perspective, studies with the same objectives should be conducted in other departments of Benin on the chronic diseases that have been identified there, so that the country has a national database. Such a base can be used in discussions between national decision-makers and technical partners to develop strategies for the appropriate management of people with chronic diseases in Benin.

Interventions on HRQoL at the Ouémé department will therefore have to take into account the disparities between urban and rural areas.

\section{Acknowledgements}

The authors are extremely grateful to all patients who were asked for their valuable time and active participation in the study.

\section{REFERENCES}

[1] Alrub, A., Hyassat, D., Khader, Y., Bani-Mustafa, R., Younes, N., \& Ajlouni K. (2019). Factors Associated with Health-Related Quality of Life among Jordanian Patients with Diabetic Foot Ulcer. Journal of Diabetes, ID 4706720 , 1-8. doi: $10.1155 / 2019 / 4706720$

[2] Brazier, J., Harper, R., \& Jones, N. (1992). Validating the SF-36 health survey questionnaire: new outcome measure for primary care. British Medical Journal, 305, 160-164.

[3] Bucquet, D. (1993). Quality of life, perceptual health, definition, concept, evaluation (2nd ed.). Paris, France: Masson.

[4] Bussières, F. (2005). The rural and urban world, two different worlds. Retrieved from http://journalagricom.ca/l e-monde-rural- et-urbain-deux-mondes-differents/

[5] Denton, M., Prus, S., \& Walters, V. (2004). Gender differences in health: a Canadian study of the psychosocial, structural and behavioural determinants of health. Social Science \& Medicine, 58(12), 2585-2600. doi:10.101/j. socscimed.2003.09.008

[6] Detmar, S., Muller, M., Schornagel, J., Wever, L., \& Aaronson, N. (2002). Health-related quality-of-life assessments and patient-physician communication: a randomized controlled trial. Journal of the American Medical Association, 288(23), 3027-3034. doi:10.1001/ jama.288.23.3027

[7] Ferrans, C. (2005). Conceptual model of health-related quality of life. Journal of Nursing Scholarship, 37(4), 336-342. Retrieved from https://www.ncbi.nlm.nih.gov/pu bmed/16396406

[8] Grover, V., Malhotra, R., Dhawan, S., Kaur, G., \& Kapoor, A. (2015). Comparative assessment of oral health related quality-of-life between rural and urban chronic periodontitis patients. Saudi Journal of Oral Sciences, 2(1), 19-24. doi: 10.4103/1658-6816.150587

[9] Gu, Y., Zhang, H., Ali, S., Huang, M., Wei, J., Gu, S., ... Hengjin, D. (2019). Social determinants of health-related quality of life among residents in Zhejiang and Qinghai, China. International Journal Environmental Research and Public Health, 16(1314), 1-14. doi: 10.3390/ijerph 160 81314

[10] INSAE. (2012). Analysis report: Integrated Modular Survey on Household Living Conditions. Retrieved from https://www.insae-bj.org/images/docs/insae-statistiques/en quetes-recensements/EMICoV/2011/Rapport-final-emicov -2011.pdf

[11] INSAE. (2015). Inequalities and Polarization of household incomes in Benin: Evolution, current status and policy measures to be implemented. Retrieved from https://www. undp.org/content/dam/benin/docs/publication/Inegalites $\% 2$ 0et $\% 20$ polarisation $\% 20$ des $\% 20$ revenus $\% 20$ des $\% 20 \mathrm{~m} \%$ c 3\%a9nages\%20au\%20Benin.pdf 
[12] Jang, E., Kim, J., Kim, K., Lee, Y., Chung, W., Kim, I., ... Sook-Hyang, J. (2018). Factors associated with health-related quality of life in Korean patients with chronic hepatitis C infection using SF-36 and EQ-5D. Gut and Liver, 12(4), 440-448. doi: 10.5009/gn117322

[13] Le Glatin, L., Hervy, Q., Guillaume, J., \& Traboulsie, A. (2017). Analysis of the quality of life related to the health status of patients consulting for osteopathic care. Review of Osteopathy, 19(3), 5-10. Retrieved from http://www.larevu e de losteopathie.com/?/ALes-numeros-de-la-revue/pqNum ero-19/aAnalyse-de-la-qualite-de-vie-liee-a-l-etat-de-santede-patients-consultant-pour-des-soins-osteopathiques/

[14] Liang, Z., Zhang, T., Lin, T., Liu, L., Wang, B., Fu, A., ... Jiang, J. (2019). Health-related quality of life among rural men and women with hypertension: assessment by the EQ-5D-5L in Jiangsu, China. Quality of Life Research, 28(8), 2069-2080. doi: 10.1007/s 11136-019-02139-3

[15] Liu, L., \& Guo, Q. (2007). Loneliness and health-related quality of life for the empty nest elderly in the rural area of a mountainous county in China. Quality of Life Research, 16, 1275-1280. doi:10.1007/s11136-007-9250-0

[16] McHorney, C., Ware, J., Lu, J., \& Sherbourne, C. (1994). The MOS 36-item short-form health survey (SF-36): III Tests of data quality, scaling assumptions, and reliability across diverse patient groups. Medical Care, 32, 40-66. doi: 10.1097/ 00005650-199401000-00004

[17] Romero, M., Sanabria, M., \& Huerfano, L. (2016). Health-related quality of life of sickle cell disease patients and families in Colombia. Value in Health, 19(3), A96. doi: 10.1016/jjval. 2016.03.1753

[18] Shin, J., Roh, D., Lee, D., Kim, S., Kim, S., \& Cho, J. (2018). Allergic rhinitis and rhinosinusitis synergistically compromise the mental health and health-related quality of life of Korean adults: A nationwide population-based survey. PLoS ONE, 13(1), e0191115. doi:10.1371/journal. pone.0191115

[19] Slim, K., Bousquet, J., \& Kwiatkowski, F. (1999). First validation of the French version of the Quality of Life Index for Digestive Diseases (GIQLI). Gastroenterology Clinical and Biology, 23, 25-31. doi: GCB-01-1999-23-1-0399 -8320-101019-ART2

[20] Sun, S., Chen, J., Johannesson, M., Kind, P., Xu, L., Zhang, Y., \& Burström, K. (2011). Regional differences in health status in China: Population health-related quality of life results from the National Health Services Survey 2008. Health Place, 17(2), 671-680. doi:10.1016/j.healthplace.20 11.01 .007

[21] Tu, X., Hwang, W., Ma, H., Chang, L., \& Hsule, S. (2017). Determinants of generic and specific health-related quality of life in patients with Parkinson's disease. PLoS ONE, 12(6), e0178896. doi: 10.1371/journal.pone.0178896.t004

[22] Tulza, K. (2017). Factors associated with health-related quality of life among Nepalese patients with Type 2 diabetes mellitus: A cross-sectional study. Journal of Institute of Medicine, 39(1), 75-81. Retrieved from https://pdfs.semanticscholar.org/07e4/ 0d367806b785b3a85477 60d4acbf9ecc7835.pdf

[23] Varkevisser, C., Pathmanathan, I., \& Brownlee, A. (1991). Designing and conducting health systems research projects: part 1 proposal development and fieldwork, International Development Research Centre. Retrieved fromhttps://idl-b nc-idrc.dspacedirect.org/bitstream/handle/10625/35108/ID L-35108.pdf? sequence $=1$ \&isAllowed $=y$

[24] Weeks, W., Kazis, L., Shen, Y., Cong, Z., Ren, X., Miller, D.,... Perlin, J. (2004). Differences in health-related quality of life in rural and urban veterans. American Journal of Public Health, 94(10), 1762-1767. doi:10.2105/ajph.94.10. 1762

[25] Weeks, W., Wallace, A., Wang, S., Lee, A., \& Kazis, L. (2006). Rural-Urban disparities in health-related quality of life within disease categories of veterans. The Journal of Rural Health, 22(3), 204-211. doi: 10.1111/j.1748-0361. 2006. 00033.x

[26] Zhang, L., Guo, X., Zhang, J., Chen, X., Zhou, C., \& Qian, D. (2017). Health-related quality of life among adults with and without hypertension: A population-based survey using EQ-5D in Shandong-China. Scientific Reports, 7(1), 1-7. doi: $10.1038 / \mathrm{s} 41598-017-15083-4$

[27] Zhang, Y., Zhou, Z., Gao, J., Wang, D., Zhang, Q., Su, M., ... Dan, Li. (2016). Health-related quality of life and its influencing factors for patients with hypertension: evidence from the urban and rural areas of Shaanxi Province, China. BMC Health Services Research, 16, 1-9. doi:10.1186/s129 13-016-1536-x

[28] Zhou, Z., Wang, C., Yang, H., Wang, X., Zheng, C., \& Wang, J. (2014). Health-related quality of life and preferred health-seeking institutions among rural elderly individuals with and without chronic conditions: A population-based study in Guangdong province, China. BioMed Research International, ID 192376, 1-10. doi: 10.1155/2014/192376 